Editorial

\title{
Institutions of Inclusion and Exclusion
}

\author{
J. Cok Vrooman ${ }^{1,3, *}$ and Marcel Coenders ${ }^{2,3}$ \\ ${ }^{1}$ Department of Sociology, Utrecht University, 3584 CH Utrecht, The Netherlands; E-Mail: j.c.vrooman@uu.nl \\ 2 Department of Interdisciplinary Social Science, Utrecht University, 3584 CH Utrecht, The Netherlands; \\ E-Mail:m.coenders@uu.nl \\ ${ }^{3}$ The Netherlands Institute for Social Research|SCP, 2594 AV The Hague, The Netherlands \\ * Corresponding author
}

Submitted: 19 February 2020 | Published: 20 March 2020

\begin{abstract}
This thematic issue aims to shed light on the connections between institutions (and related forms of organisation) and social inclusion and exclusion. In this editorial we briefly introduce the concepts, summarise the various articles and provide some general conclusions.
\end{abstract}

\section{Keywords}

institutions; organisations; social inclusion; social exclusion; welfare state

\section{Issue}

This editorial is part of the issue "Institutions of Inclusion and Exclusion" edited by J. Cok Vrooman (Utrecht University, The Netherlands/The Netherlands Institute for Social Research|SCP, The Netherlands) and Marcel Coenders (Utrecht University, The Netherlands/The Netherlands Institute for Social Research |SCP, The Netherlands).

(C) 2020 by the authors; licensee Cogitatio (Lisbon, Portugal). This article is licensed under a Creative Commons Attribution 4.0 International License (CC BY).

\section{Introduction}

In this thematic issue we explore the complex and manifold links between institutions and issues of social inclusion and exclusion. Institutions refer to the formal and informal rules of society, in the form of legislation on the one hand, and values, social norms, conventions and contracts between private parties on the other (Vrooman, 2009). North (1990, p. 3) described institutions as "the rules of the game in society, or, more formally, humanly devised constraints that shape human interaction." In his view, institutions foster cooperation, coordination, trust and lower transaction costs among economic actors. Informal institutions arise to coordinate repeated social and economic interaction. In addition, if this serves a collective purpose, the government may lay down certain rules in formal laws and regulations, such as property rights or welfare entitlements. It then acts as a thirdparty enforcer, a role the government can perform due to its monopoly on legislation and its means to monitor and enforce compliance through auditors, the police, the judiciary and the military. Bowles (2004, pp. 47-48) emphasizes that institutions have wider social benefits. According to him they concern "the laws, informal rules, and conventions that give a durable structure to social interactions among the members of a population." Scott (2008, p. 45) goes one step further by stating that "institutions are comprised of regulatory, normative and cultural-cognitive elements, that together with associated activities and resources, provide stability and meaning to social life." For him, therefore, institutions matter not only because of their 'regulatory' aspects (behavioural constraints, or rules that enable people), but also due to the judgments and perceptions of social reality that the existing rules imply. Moreover, institutions are often linked to the allocation of certain resources, and people and organisations must act according to the rules (these must be 'enacted') if they are to be effective. Following Scott's definition, institutions therefore not only bring about economic coordination and social stability; theoretically they also create a meaningful social order and affect social inequality and cohesion. 
Institutions tend to be closely aligned to various forms of organisation: the formation and configuration of social groups (e.g., local community networks) and collective actors (e.g., businesses, welfare agencies, hospitals, schools). If institutions are the rules of the game in society, individuals and organisations are the game's players. Adequate organisation is a prerequisite for effective institutions.

The existing institutions provide an opportunity structure to which people and organisations tend to respond and adapt. However, they are not merely rule takers, but also rule makers: Actors typically try to change the rules in order to obtain a better fit with their interests, preferences, and ideals, partly through their participation in different policy arenas.

Institutions and their related forms of organisation are theoretically important as they structure society in terms of the life chances, perceptions, preferences and ideas of citizens and policy actors. In doing so, institutions may have an emancipatory or a restrictive nature; that is, they may enhance the inclusion, but can also lead to the exclusion of certain segments of the population, according to their social class, age, ethnic origin, religion, gender, sexual orientation, health status or appearance. Institutions and organisations are key elements of welfare provisions that aim to stimulate the inclusion of citizens, or to combat their exclusion. Such rules may relate to state-guaranteed rights on social security, health provisions, education or affordable housing, etc., but also to social claims and obligations regarding the provision of informal care within families and neighbourhoods.

Generally speaking, social exclusion refers to people who experience an accumulation of disadvantage in the society in which they live; and social inclusion is often used to denote policy interventions or behavioural processes that aim to prevent such a state of affairs. A closer look at the literature reveals that the concepts have at least four different meanings (see, for instance, Atkinson, Cantillon, Marlier, \& Nolan, 2002; Burchard, 2000; Hills, le Grand, \& Piachaud, 2002; Jehoel-Gijsbers \& Vrooman, 2007; Levitas, 2006; Room, 1997; Vrooman \& Hoff, 2013; Vrooman, Hoff, \& Guiaux, 2015). First of all, they can refer to the rules and organisational forms that (do not) enable people to become a full-fledged member of society. Conceived in this way, inclusion and exclusion are a matter of social infrastructure. A notion such as the 'inclusive society' often refers to certain entitlements, obligations and modes of delivery, for instance those aiming to realize human rights or to achieve equality of opportunity in education and on the labour market. In this meaning, inclusion and exclusion are largely synonymous with institutions and the connected types of organisation.

In a second sense, social inclusion and exclusion refer to perceptions and behavioural processes: How do actors stimulate that (groups of) people are included or excluded? This concerns the negative and positive discrimination of certain groups, the non-take up and abuse of regulations and provisions, and implementation prob- lems in social security, health care, education and housing. These process-related agency aspects of inclusion and exclusion involve the perceptions and behaviour of businesses, public authorities, groups of citizens, and individuals (forms of 'self-exclusion,' such as withdrawing from social contacts or benefit fraud).

In a third meaning, inclusion and exclusion refer to societal outcomes. Here one may distinguish a structural or distributive component (that connects with issues of social inequality) from the cultural-integrative aspects, which relate to issues of social cohesion and identity (Jehoel-Gijsbers \& Vrooman, 2007). Do groups of citizens experience relative deprivation, or do they not realize minimum social standards, such as a sufficient income, adequate housing, an acceptable health status, the knowledge and skills the labour market and wider society require, etc.? To what extent are people part of key associations in society, such as the school, the working environment, political and community organisations, volunteer work, social media? Are there (digital) bubbles of like-minded people, with strong mutual but weak external connections? Do groups experience that they are outside of mainstream society?

Finally, inclusion and exclusion can also relate to an individual's meaningful connectedness to others. Do people have significant social relationships, do they feel lonely or not? This concerns a different issue than the previous meaning of inclusion and exclusion, the societal outcomes. If citizens do not participate in societies' key associations, they can be lonely; but that is not necessary, as in the case of a recluse who chooses to be so voluntarily. Conversely, people who are socially isolated run a greater risk of not taking part in relationships that are deemed important in their role as citizens. However, that also does not occur automatically: someone who meets few others privately and feels lonely may very well perform adequately in their role as an employee.

\section{Overview of the Contributions}

The relationship between institutions, organisations and various forms of social inclusion and exclusion is the overarching theme of this thematic issue. It contains theorydriven empirical contributions from several disciplines. Benneker, Gërxhani, and Steinmetz (2020) investigate the role social norms play in state compliance with a human rights treaty aiming to assure active and passive female voting rights: article 7a of the Convention on the Elimination of all forms of Discrimination Against Women (CEDAW). They combine new institutionalist theory with a comparative perspective on human rights. In terms of the conceptual framework that was outlined above, this contribution focuses on political in- and exclusion as a societal outcome. It starts out from the hypothesis that the effectiveness of formal regulation (the implementation of the state's CEDAW obligation to enhance female political participation) is likely to depend on the prevailing domestic informal institutions. Populations may obstruct 
human rights treaties that do not align with dominant social norms, and this makes it less probable that national authorities will effectively implement them after ratification. If social norms are in line with a treaty's objectives, a higher degree of state compliance is expected.

Benneker et al. (2020) first perform a multi-level regression analysis on data drawn from the World Values Survey, covering 73 countries in three waves between 1996 and 2007. Their main explanatory variable is conservativeness of the social norm on female political participation, as measured by the item 'on the whole, men make better political leaders than women do'. State compliance with the CEDAW stipulations has been operationalized by the percentage of seats held by women in the national parliament. Controlling for other variables, the authors find a consistent and statistically significant relationship between conservative political gender norms and non-compliance with the aims of the human rights treaty. A subsequent qualitative study suggests that a change towards less restrictive social norms and more state compliance can be brought about by bargaining processes, where the resources held by change agents within and outside of the community are likely to be decisive. Benneker et al. (2020) conclude that social norms need to be added as an explanatory factor in understanding state compliance with human rights treaties. This implies a pivotal role for informal institutions: What people think is right is crucial for realizing the state's formal obligation to safeguard human rights.

Crul, Steinmetz, and Lelie (2020) expand on the debate regarding the interethnic contact hypothesis that originates in the work of Allport. They explore whether the physical architecture of neighbourhoods contributes to interethnic social tensions, or the absence thereof. In their article they posit that intergroup contacts and attitudes may not only be shaped by human conditions in a neighbourhood (differences in composition of the population, status and power relationships, etc.), but also by its physical and spatial characteristics. From an institutional perspective, this sheds light on an often neglected part of societies' rules: the regulatory impact of physical design on human interaction, which links to the New Urbanism school in architecture and to the lively debate on 'nudging' in behavioural economics (Thaler \& Sunstein, 2008).

Crul et al. (2020) study how the socially constructed physical infrastructure can enhance local processes of in- and exclusion, and how this translates into cultural (dis)integration at community level. Using both quantitative and qualitative data (the Dutch TIES survey and a municipal survey, plus interviews) they focus on ethnically diverse working-class neighbourhood in Amsterdam that are rather similar in their ethnic composition but differ in terms of architecture and perceived ethnic tensions. The latter is higher among inhabitants of Dutch descent living in suburban neighbourhoods than among their counterparts in equally diverse inner-city neighbourhoods. The suburban group also feels more threat- ened by ethnic diversity and more often attributes neighbourhood conflicts to ethnic and cultural differences (and not to clashes between, e.g., loitering youth and older inhabitants). The outcomes suggest that these contrasts are related to differences in architectural design that impact on everyday contacts, in particular the use of semi-public spaces. Inhabitants of inner-city working class neighbourhoods share less galleries, inner court yards, garages, elevators, etc., than their suburban counterparts, and thereby have less unavoidable contacts with other people. The interethnic contacts that do occur in the inner city location may be more voluntarily engaged in. However, architecture is not the sole driving factor. Previous experience with ethnic diversity, and positive or negative attitudes towards this phenomenon, also turn out to matter for understanding perceived ethnic tensions, as is participation in local forms of organisation. This indicates that many conditions have to coincide before ethnic tensions will escalate, and that the physical conditions of housing and neighbourhoods should be part of the theoretical framework.

Velterop, van der Klink, Brouwer, Oldenhuis, and Polstra (2020) analyse what valuable functionings older long-term unemployed people strive for, and to what extent they are able to realise these. Their contribution is based on semi-structured interviews conducted in the Netherlands and builds on Sen's capability approach and Jahoda's latent deprivation theory. Social exclusion is regarded as a capability failure that may spread out to various functionings. The analysis mainly focuses on the individual aspects of in- and exclusion and on the behavioural processes that are involved. In terms of institutions, Velterop et al. (2020) look at the informal work values of the unemployed. In addition, they position their outcomes within the dominant paradigm of the formal welfare system. This consisted not only of ever tighter eligibility criteria and reductions of the level and duration of benefits, but also of a growing emphasis on strict monitoring and rule enforcement among benefit recipients.

The study identified nine valuable functionings among older unemployed people: social contact, feeling appreciated, structure, feeling useful, meaningfulness, autonomy, financial resources, paid work and being active. In addition, the respondents consisted of three distinct groups. Two of these experienced a change in work status when they started to receive benefits, but they reacted differently. The first group still considered paid work as valuable, and these people experienced the most difficulties in achieving their valued outcomes. The second group adapted to their new situation by attributing greater value to other functionings. A third group had no change in work status (e.g., because they already were jobless and came to depend on a benefit after a divorce) and did not try to realize other functionings. Social exclusion was most prominent among those who still experienced a worker identity. In order to combat social exclusion, Velterop et al. (2020) propose a tailormade approach that takes the valued outcomes of long-term un- 
employed persons as a starting point. In formal welfare systems this could require a paradigm shift, where workfare and activation are replaced by social investments aiming to capacitate people.

Walker and Thunus (2020) draw on Luhmann's systems theory and on a grounded theory approach to explore the inclusiveness of mental health care in a context of extramuralisation. In their article they focus on people with complex and chronic mental health problems (PCCS), who in many countries nowadays face higher thresholds in their access to formal mental health care. However, it is not self-evident that alternative informal arrangements will be able to secure the integration of this vulnerable group in society at large. Conceptually, this contribution analyses tensions and complementarities between formal and informal mental health care organisations, in relation to a reform of the legal system that was implemented in Belgium in 2010. The revision sought to connect formal mental care (psychiatric hospitals, sheltered housing, psychiatric nursing homes) with alternative community-based services that emphasize personal autonomy and social inclusion. The article uses the second concept mainly in terms of accessibility (the possibilities to find mental care), agency (interactions, role perceptions and language) and the individual experience of discrimination and integration in mental care organisations and the local community.

The findings of Walker and Thunus (2020) point at two distinct systems. Within formal mental care, the ideal-typical 'patient role' was performed by people who endorsed the medical interpretation of their mental distress. Social inclusion was mainly experienced within the confines of the formal mental care organisation, and in relation to empathic close relations who subscribed to the medical diagnosis. Outside the formal system, however, taking up the patient role could be problematic; for instance, identifying yourself as a person with complex and chronic mental health problems tends to make it difficult to find a regular job. 'Impatient' role performers distance themselves from the medicalization of their personal situation. In the context of formal mental care this challenges the system's boundaries, and may imply a form of self-exclusion; but in alternative services it allows PCCs to 'de-specify' their mental impairments, to focus on their possibilities to connect with the community, and to explore new roles in other social systems. Based on this, Walker and Thunus (2020) stress the potential of both formal and informal mental care. A precondition is that these systems maintain their distinct logic and modes of operation-as they need these to survive-and supplement one another, with the aim to mediate between people with mental health problems and different social environments. That would also allow PCCs to alternate between patient and impatient roles at different stages of their life course.

Vriens and De Moor (2020) apply a sociological perspective to new insurance arrangements with strong peer-to-peer involvement, such as Friendsurance,
Lemonade and 'Broodfondsen.' These are technologydriven alternatives to traditional forms of public and commercial insurance, often with the aim to be innovative, fairer, more transparent and more social. They may be seen as a re-invention of 19th century forms of mutual insurance associations. The study focuses on informal types of organisation (mutuals as an alternative form of insurance delivery) and on informal rules (especially the use of risk differentiation, reinsurance and the redistribution of contributions among the participants by private actors). The social exclusion element mainly refers to infrastructural aspects: Do these new initiatives set limits to group size and set up and promote new forms of communication? Applying a worldwide approach, Vriens and De Moor (2020) identified 57 new mutuals in the 2006-2018 period. Of these, 21 were no longer active by 2019 and therefore may be considered as failed initiatives. From the remaining 36 they selected 11 mutuals with sufficient information for allowing a closer inspection of their institutional, resource and member characteristics. Most of these organisations were still rather small (typically less than 2,000 participants or policyholders), with only the Bread Funds ( $>20,000$ members), Friendsurance (about 150,000) and Lemonade (about 425,000 ) having a substantial funding base.

Through their analysis, Vriens and De Moor (2020) identify two main categories of mutuals. The first type resembles their 19th century counterparts most closely. Here members are wholly or partly responsible for governance, risk differentiation is lacking, and financial contributions are flat rate and low. Correspondingly, insurance pay-outs in these bottom-up initiatives are basic and cannot be guaranteed. The second type is more similar to existing commercial insurance companies. Although these also apply direct risk sharing at group level and redistribute unused premiums among the participants, they have a top-down governance model with sophisticated risk differentiation based on modern insurance technology. These two types of mutuals face different challenges, which partly reflect problems that were already encountered by their historical predecessors. In the bottom-up type (e.g., the Dutch Bread Funds), adverse selection may occur, and this is problematic once the number of claims exceeds the financial carrying capacity. For mutuals of the top-down type, such as Lemonade and Friendsurance, the main test will be if they can preserve the feelings of solidarity and trust among their participants. These reduce moral hazard but may become less effective once the mutuals grow further, and risksharing becomes more abstract and anonymous.

\section{Conclusion}

This issue clearly highlights the breadth of the Institutions of Inclusion and Exclusion theme. Theoretically, the contributions are based on various perspectives. In addition to the dominant 'new institutionalism,' they have been inspired by comparative hu- 
man rights theory, the Interethnic contact hypothesis, Sen's capability approach, Jahoda's work on relative deprivation and Luhmann's system theory. Various aspects of social inclusion and exclusion are examined: It is not only about the infrastructural side (the behavioural limitations and opportunities that people face, and related organisational forms), but also about behavioural processes and outcomes for individuals and wider society. The analyses carried out are both quantitative and qualitative, and cover such diverse topics as the political participation of women, interethnic conflicts in neighbourhoods, the lives that long-term unemployed elderly people aspire and lead, the social integration of people with complex and chronic mental health problems, and peerto-peer models as a social and innovative alternative to traditional forms of public or commercial insurance.

Given the many meanings of the concepts 'institutions,' 'inclusion' and 'exclusion' that we have distinguished above, this wide scope is not entirely unexpected, but it can make it difficult to draw overarching conclusions. Nevertheless, a number of lessons stand out. First of all, irrespective of the elements of the concepts central to the contributions, a common finding is that institutions matter for understanding social inclusion and exclusion. In addition, the complex theoretical and empirical relationship between formal and informal institutions is a recurring theme. The informal rules sometimes prove to be conditional for a successful implementation of formal institutions (Benneker et al., 2020), but can also be a competing regulatory system (Vriens \& De Moor, 2020; Walker \& Thunus, 2020) or be aimed at goals other than policy makers seek to achieve through formal legislation (Velterop et al., 2020). Another common result that emerges from the articles in this thematic issue is that formal rules are often not enough if one wants to promote that people are full-fledged members of society, or if one strives to combat social exclusion. In order to achieve this, one should take into account, for example, possible conflicts with the dominant expectations among citizens (Benneker et al., 2020; Velterop et al., 2020), the limitations and opportunities arising from the physical environment in which human behaviour takes place (Crul et al., 2020), and the limitations and idiosyncratic institutional logic of different systems (Walker \& Thunus, 2020). Conversely, informal ways of provision, however innovative, are not necessarily more inclusive than traditional public or commercial arrangements. Just like these, they may be confronted with adverse selection, moral hazard and risk differentiation.

For the future research agenda, it is desirable to systematically link the various aspects of institutions and of inclusion and exclusion that we have recognized here. Specific attention should also be paid to:

1. Institutional complementarity: How do formal and informal rules regarding work, health and social care, education, housing, legal aid, etc., jointly affect the social position of groups of citizens?
2. Agency: What do actors do, given the systems of behavioural regulation and enablement in which they find themselves? To what extent do they succeed in re-aligning the rules with their own interests, preferences, ideals, etc.?

3. The intersectionality of forms of inclusion and exclusion: The conjuncture of social class, age, ethnic origin, religion, gender, sexual orientation, health status and appearance as factors that bring about social inclusion and exclusion.

Such an approach would also do justice to the growing importance that policymakers attach to the relationship between different forms of institutionalization on the one hand, and issues of social inequality and social cohesion on the other. This is reflected, for example, in ideas about the social investment state and inclusive growth (Hemerijck, 2018; Mahon, 2019; Morel, Palier, \& Palme, 2012) that have been adopted by organisations such as the OECD and the World Bank in recent years.

\section{Conflict of Interests}

The authors declare no conflict of interests.

\section{References}

Atkinson, T., Cantillon, B., Marlier, E., \& Nolan, B. (2002). Social indicators: The EU and social exclusion. Oxford: Oxford University Press.

Benneker, V., Gërxhani, K., \& Steinmetz, S. (2020). Enforcing your own human rights? The role of social norms in compliance with human rights treaties. Social Inclusion, 8(1), 184-193.

Bowles, S. (2004). Microeconomics: Behavior, institutions, and evolution. Princeton, NJ: Princeton University Press.

Burchard, T. (2000). Social exclusion: Concepts and evidence. In D. Gordon \& P. Townsend (Eds.), Breadline Europe: The measurement of poverty (pp. 385-406). Bristol: The Policy Press.

Crul, M., Steinmetz, C. H. D., \& Lelie, F. (2020). How the architecture of housing blocks amplifies or dampens interethnic tensions in ethnically diverse neighbourhoods. Social Inclusion, 8(1), 194-202.

Hemerijck, A. (2018). Social investment as a policy paradigm. Journal of European Public Policy, 25(6), 810-827.

Hills, J., le Grand, J., \& Piachaud, D. (2002). Understanding social exclusion. Oxford: Oxford University Press.

Jehoel-Gijsbers, G., \& Vrooman, C. (2007). Explaining social exclusion: A theoretical model tested in the Netherlands. The Hague: The Netherlands Institute for Social Research |SCP.

Levitas, R. (2006). The concept and measurement of social exclusion. In C. Pantazis, D. Gordon, \& R. Levitas (Eds.), Poverty and social exclusion in Britain: The 
millennium survey (pp. 123-160). Bristol: The Policy Press.

Mahon, R. (2019). Broadening the social investment agenda: The OECD, the World Bank and inclusive growth. Global Social Policy, 19(1/2), 121-138.

Morel, N., Palier, B., \& Palme, J. (Eds.). (2012). Towards a social investment welfare state? Ideas, policies, challenges. Bristol: Policy Press.

North, D. C. (1990). Institutions, institutional change and economic performance. Cambridge: Cambridge University Press.

Room, G. (1997). Social quality in Europe: Perspectives on social exclusion. In W. Beck, L. van de Maesen, \& A. Walker (Eds.), The social quality of Europe. The Hague: Kluwer Law International.

Scott, W. R. (2008). Institutions and organizations (3rd ed.). London: Sage.

Thaler, R. H., \& Sunstein, C. (2008). Nudge: Improving decisions about health, wealth, and happiness. New Haven, CT: Yale University Press.

Velterop, N., van der Klink, J., Brouwer, S., Oldenhuis, H.,
\& Polstra, L. (2020). Factors influencing the ability to achieve valued outcomes among older long-term unemployed people. Social Inclusion, 8(1), 203-213.

Vriens, E., \& De Moor, T. (2020). Mutuals on the move: Exclusion processes in the welfare state and the rediscovery of mutualism. Social Inclusion, 8(1), 225-237.

Vrooman, J. C. (2009). Rules of relief: Institutions of social security, and their impact. The Hague: The Netherlands Institute for Social Research |SCP.

Vrooman, J. C., \& Hoff, S. J. M. (2013). The disadvantaged among the Dutch: A survey approach to the multidimensional measurement of social exclusion. Social Indicators Research, 39(3), 1261-1287.

Vrooman, J. C., Hoff, S. J. M., \& Guiaux, M. (2015). Descendants of hardship: Prevalence, drivers and scarring effects of social exclusion in childhood. Social Inclusion, 3(4), 76-97.

Walker, C. H., \& Thunus, S. (2020). Meeting boundaries: Exploring the faces of social inclusion beyond mental health systems. Social Inclusion, 8(1), 214-224.

\section{About the Authors}

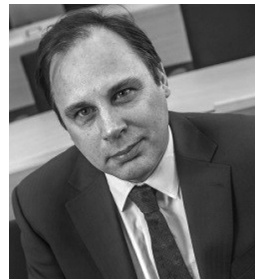

J. Cok Vrooman is Professor of Social Security and Participation at Utrecht University and Chief Scientific Strategist at The Netherlands Institute for Social Research|SCP, a scientific advisory to the Dutch government. He obtained a master's degree from Erasmus University and a PhD in Sociology from Tilburg University (both cum laude) and was a board member of the Dutch Sociological Association. His main research interests concern institutions, welfare regimes, social security, labor market, pensions, poverty, social exclusion and social inequality. Publications include Rules of Relief (2009), Regimes and Cultures of Social Security (2012), Descendants of Hardship (2015) and his inaugural lecture Taking Part in Uncertainty (2016).

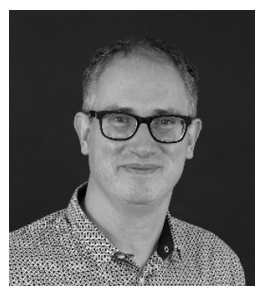

Marcel Coenders is Associate Professor of Interdisciplinary Social Science at Utrecht University and Chief Scientific Strategist at The Netherlands Institute for Social Research|SCP, a scientific advisory to the Dutch government. His main research interests include processes of in- and exclusion, in particular with regard to migrants and minorities, national identity, solidarity, and prejudice and discrimination at the labour market. 